\title{
AVALIAÇÃO DA APRENDIZAGEM DE ALUNOS COM DEFICIÊNCIA INTELECTUAL: LEVANTAMENTO BIBLIOGRÁFICO (2007-2020)
}

\section{ASSESSMENT OF LEARNING OF STUDENTS WITH INTELLECTUAL DISABILITIES: BIBLIOGRAPHIC SURVEY (2007-2020)}

\section{Ana Carla Santos}

Especialista em Literatura e Ensino de Literatura pela Universidade Estadual do Sudoeste da Bahia (UESB), graduada em Letras Vernáculas pela mesma instituição e professora da rede municipal de Maracás - BA, Brasil. E-mail: anakarla moreninha@hotmail.com

Vitória Vieira de Oliveira Kurtz de Azevedo Graduada em Letras - Língua Portuguesa pela Universidade Católica de Pelotas (UCPel) e professora da rede municipal de Pelotas - RS, Brasil.

E-mail: vitoria.zvs@gmail.com

Marcela de Melo Fernandes

Mestre em Educação Cultura e Organizações Sociais (FUNEDI- UEMG) e professora da Disciplina Teorias da Aprendizagem do IFMG campus Avançado Arcos, Brasil. ORCID: https://orcid.org/0000-0002-4144-3380?lang=en E-mail: marcela.fernandes@ifmg.edu.br

Recebido: 16/06/2021 - Aceito: 17/06/2021

\section{Resumo:}

O presente estudo tem por objetivo refletir sobre a avaliação escolar de alunos com deficiência intelectual nas escolas regulares brasileiras. Assim, buscou-se entender como foi realizada a proposta de avaliação desses alunos desde a Lei da Inclusão 


\section{$2021 / 02$}

\section{ISSN 2178-6925}

de 2007, que levou efetivamente os alunos com deficiência às classes regulares. Logo, o estudo apresentará uma síntese de como vem sendo definido esse processo. A metodologia utilizada foi a pesquisa bibliográfica, a qual, segundo Marconi e Lakatos, (1991) diz respeito ao levantamento de toda a bibliografia já publicada e que tenha relação com o tema em estudo. Assim, foi realizado um recorte temporal que contemplou obras e publicações do período de 2007 a 2020. Portanto, foram analisadas vinte e uma (21) obras ao todo, distribuídas em sete (7) artigos científicos, oito (8) dissertações de mestrado, uma (1) tese de doutorado e cinco (5) capítulos de livros. Por fim, concluiu-se, dentre outras coisas, que os alunos com deficiência intelectual têm suas especificidades e um ritmo próprio de aprendizagem que merece um olhar diferenciado pela instituição de ensino como um todo.

Palavras-chave: Inclusão; Deficiência intelectual; Avaliação.

\section{Abstract:}

The present study aims to reflect on the school evaluation of students with intellectual disabilities in regular Brazilian schools. Thus, we sought to understand how the proposal for evaluating these students was carried out since the Inclusion Law of 2007, which effectively took students with disabilities to regular classes. Therefore, the study will present a summary of how this process has been defined. The methodology used was the bibliographic research, which, according to Marconi e Lakatos, (1991) refers to the survey of all the bibliography already published and which is related to the subject under study. Thus, a time frame was carried out that included works and publications from 2007 to 2020. Therefore, twenty-one (21) works in total were analyzed, distributed in seven (7) scientific articles, eight (8) master's dissertations, one (1) doctoral thesis and five (5) book chapters. Finally, it was concluded, among other things, that students with intellectual disabilities have their specificities and their own learning pace that deserve a different look by the educational institution.

Keywords: Inclusion; Intellectual disability; Evaluation.

\section{INTRODUÇÃO}

A educação é feita de protótipos, ou seja, maneiras diferentes de idealizar e abranger a realidade. Hoje em dia, o mais novo paradigma educacional é a inclusão escolar, que defende o direito a educação a todos os alunos, em todos os níveis educacionais. 
Partindo desse paradigma, a ideia de uma sociedade inclusiva surgiu em meados do século $\mathrm{XX}$, com o fortalecimento das críticas à segregação de estudantes que eram encaminhados para ambientes especiais.

Assim, a Educação Inclusiva não é uma conquista recente, já que surgiu ainda no século passado, através de uma lei denominada "Princípio da normalização", proposta na Dinamarca, em 1959 (NOGUEIRA, CARNEIRO e SOARES, 2017). No Brasil, Paulo Freire (2006), com o objetivo de diminuir as diferenças, desde a década de 60 trazia reflexões de inegável relevância. Freire tece uma dura e palpável crítica e, ao mesmo tempo, uma minuciosa análise da educação, buscando uma prática pedagógica reveladora, na qual se via no educando o próprio sujeito de sua educação.

Ao longo dos anos, diversos documentos, Leis e Decretos foram surgindo e através de seu caráter normativo, puderam garantir que a Educação Inclusiva se efetivasse. Além disso, é inegável a importância do conhecimento científico quando se fala em alunos com deficiência, já que as pesquisas e os estudos realizados ao longo do tempo contribuíram para se lançar um novo olhar sobre esses sujeitos, anteriormente excluídos de todos os segmentos da sociedade. Assim sendo, pretende-se, neste trabalho, em um primeiro momento, caracterizar os alunos com deficiência intelectual e, em seguida, expor os documentos normativos que deram conta da Educação Inclusiva.

Logo, no contexto de uma Educação Inclusiva, o presente trabalho tem por objetivo analisar a avaliação escolar de alunos com deficiência intelectual nas escolas regulares brasileiras, buscando, assim, entender como a avaliação da aprendizagem desses alunos vem sendo proposta por diferentes estudiosos, desde a Lei da Inclusão de 2007.

Logo, espera-se que este estudo possa servir de conhecimento e apoio para professores e estudiosos da área.

\section{BREVES CONSIDERAÇÕES SOBRE A DEFICIÊNCIA INTELECTUAL}




\section{$2021 / 02$}

\section{ISSN 2178-6925}

Antes de falar a respeito da deficiência intelectual, cabe aqui explicitar brevemente o que se entende por alunos com deficiência. Nesse viés, a Política Nacional de Educação Especial na perspectiva da Educação Inclusiva (BRASIL, 2008) nos diz que:

Consideram-se alunos com deficiência àqueles que têm impedimentos de longo prazo, de natureza física, mental, intelectual ou sensorial, que em interação com diversas barreiras podem ter restringida sua participação plena e efetiva na escola e na sociedade (BRASIL, 2008, p. 15).

No que tange à terminologia deficiência intelectual, Pletsch e Oliveira (2013) explicam que esse conceito tem sofrido uma série de revisões influenciadas pelas convenções sociais e científicas de cada época: de idiotia (século XIX), debilidade mental e infradotação (início do século $\mathrm{XX}$ ), imbecilidade e retardo mental (com seus níveis leve, moderado, severo e profundo), deficiência mental, usado no final do século XX, até déficit intelectual, a partir dos anos 2000. Já o termo deficiência intelectual, segundo eles, é recente na literatura e foi disseminado durante a Conferência Internacional sobre Deficiência Intelectual, realizada no Canadá, evento que originou a Declaração Internacional de Montreal sobre Inclusão.

Os mesmos autores afirmam que

O uso do referido termo também vem sendo recomendado pela Associação Internacional de Estudos Científicos das Deficiências Intelectuais - International Association for the Scientific Study of Intellectual Disabilities (IASSID). Além disso, desde 2010, ele vem sendo indicado pela Associação Americana de Deficiência Intelectual e Desenvolvimento (AADID, 2010), entidade que historicamente vem influenciando as classificações adotadas pela Organização Mundial de Saúde e a Associação Americana de Psicologia (APA) (PLETSCH E OLIVEIRA, 2013, p. 62).

Hoje em dia, o termo deficiência intelectual pode ser encontrado em trabalhos que tratam do assunto, uma vez que essa denominação passou a ser utilizada oficialmente no Brasil. Ainda, sobre essa mudança de terminologia, Pletsch e Glat (2012), comentam que, para diversos autores, não se trata apenas de substituí-la por um termo menos estigmatizante, mas sim, "representa um novo 


\section{$2021 / 02$}

\section{ISSN 2178-6925}

paradigma em termos de definição do construto da deficiência intelectual, em processo desde a definição e classificação apresentada pela então AAMR em 2002" (PLETSCH; GLAT, 2012, p. 196).

No que concerne aos alunos com deficiência intelectual, esses se caracterizam, segundo a $11^{\text {a }}$ edição da Associação Americana de Deficiência Intelectual Desenvolvimento (AADID), por terem "[...] limitações significativas tanto no funcionamento intelectual como na conduta adaptativa e está expresso nas habilidades práticas, sociais e conceituais, originando-se antes dos dezoito anos de idade" (AADID, 2010 apud PLETSCH e OLIVEIRA, 2013, p. 31). Tal definição, cabe ressaltar, não é imutável, mas, ao contrário, passível de mudança conforme o próprio ser humano se modifica e modifica o contexto em que está inserido.

Diversos estudiosos apontam a complexidade que se encontra ao tentar definir a deficiência intelectual, assim como expõem as diferentes visões de diferentes áreas que buscam defini-la1.

Para Duarte (2018), existe uma prevalência da deficiência intelectual em sujeitos do sexo masculino e nas classes socioeconômicas menos favorecidas. A mesma autora afirma que a deficiência intelectual deve ser diagnosticada a partir dos cinco e antes dos 18 anos de idade, através de avaliação psicológica que envolva avaliação clínica e testes de inteligência padronizados e individualizados.

Assim, a deficiência intelectual, uma vez diagnosticada, é classificada em termos de coeficiente de inteligência que determina os seguintes níveis:

a. Leve: QI entre 50-70 - CID F70

b. Moderado: QI entre 36-50 - CID F71

c. Grave: QI entre 20-35 - CID F72

d. Profundo: QI inferior a 20 - CID F73

\footnotetext{
${ }^{1}$ Pode-se conferir mais a respeito das concepções sobre a deficiência intelectual no documento intitulado "Formação Continuada a Distância de Professores para o Atendimento Educacional Especializado Deficiência Mental" (BRASIL, 2007), cuja referência encontra-se no fim deste trabalho.
} 


\section{1/02}

\section{ISSN 2178-6925}

O diagnóstico da deficiência intelectual leva diversos desafios à escola e aos professores em sala de aula, uma vez que o aluno com essa deficiência lida de uma maneira própria com o saber que não é aquela esperada pela escola. Nenhuma outra deficiência abala tanto a escola, pois não toca no cerne de sua transformação como faz a deficiência intelectual, que é "considerar a aprendizagem e a construção do conhecimento acadêmico como uma conquista individual e intransferível do aprendiz que não cabe em padrões e modelos idealizados" (BRASIL, 2007, p. 16). Nesse sentido, diversos estudos recentes têm concebido a deficiência intelectual não em termos de limitações de seus portadores, mas sim em termos de "nível de apoio que ele irá necessitar ao desempenhar atividades sociais" (ALLES et. al., 2019, p. 381). Tais definições incidem diretamente sobre o conceito de avaliação desses sujeitos, o que será discutido detalhadamente mais adiante.

\section{MARCOS LEGAIS E NORMATIVOS: HISTÓRICO DA EDUCAÇÃO INCLUSIVA NO BRASIL}

A Educação Inclusiva busca uma educação justa e igualitária para todos. Pensar a escola numa perspectiva inclusiva é universalizar o acesso para esse público e garantir todos os seus direitos. $O$ atendimento às pessoas com deficiência no Brasil iniciou-se com a criação do Imperial Instituto dos Meninos Cegos, em 1854, atual Instituto Benjamin Constant - IBC, e o Instituto dos Surdos Mudos, em 1857, hoje denominado Instituto Nacional da Educação dos Surdos INES, ambos no Rio de Janeiro².

A primeira referência que se tem sobre a Educação Especial aparece no artigo 88 da Lei de Diretrizes e Bases da Educação Nacional (LDBEN) - Lei № 4.024/61 que fundamentava o atendimento educacional às pessoas com

\footnotetext{
${ }^{2}$ Ver Política Nacional de Educação Especial na Perspectiva da Educação Inclusiva. Brasília: MEC/2008.
} 
deficiência, chamado de "educação de excepcionais" e tinha como finalidade integrá-los na comunidade.

A Constituição Federal de 1988 é um avanço para a universalização do ensino. No seu artigo 206, inciso I, estabelece a "igualdade de condições de acesso e permanência na escola" e, em seu artigo 208, afirma "a garantia de atendimento educacional especializado aos portadores de deficiência, preferencialmente na rede regular de ensino". Ainda pensando na integração social dos portadores de deficiência, a Lei № 7.853/89 traz a Educação Especial como modalidade educativa que deve ser inclusa no sistema educacional.

O grande movimento pela inclusão começa na década de 90, como forma de integração. Falava-se muito em inclusão, mas os alunos ainda eram distribuídos em salas especiais. Alguns documentos começam, então, a surgir com a pretensão de influenciar políticas públicas para a Educação Inclusiva. Em 1994, a Declaração de Salamanca afirma que "toda criança tem direito fundamental à educação, e deve ser dada a oportunidade de atingir e manter o nível adequado de aprendizagem" e ainda que "toda criança possui características, interesses, habilidades e necessidades de aprendizagem que são únicas”.

A Educação Inclusiva é um desafio e suas especialidades merecem um olhar diferenciado. É imprescindível ressignificar valores e identificar como a exclusão ocorre dentro da escola. A publicação da Política Nacional de Educação Especial, em 1994, orienta o processo de "integração instrucional" que condiciona o acesso às classes comuns do ensino regular àqueles que "(...) possuem condições de acompanhar e desenvolver as atividades curriculares programadas do ensino comum, no mesmo ritmo que os alunos ditos normais". ${ }^{3}$

A Lei de Diretrizes e Bases da Educação (LDB) Lei № 9.394/96 traz o capítulo V específico para a Educação Especial. Segundo o artigo 58:

Entende-se por educação especial, para os efeitos desta Lei, a
modalidade de educação escolar oferecida preferencialmente na rede
regular de ensino, para educandos com deficiência, transtornos globais do

${ }^{3}$ Ver Política Nacional de Educação Especial na Perspectiva da Educação Inclusiva. Brasília: $\mathrm{MEC} / 2008$ 


\section{$2021 / 02$}

\section{ISSN 2178-6925}

desenvolvimento e altas habilidades ou superdotação. ${ }^{4}$ (BRASIL, 1996, art. 58).

A LDB traz grandes contribuições para a Educação Inclusiva. Ainda nesse artigo, ela afirma que "o atendimento educacional será feito em classes, escolas ou serviços especializados, sempre que, em função das condições específicas dos alunos, não for possível a sua integração nas classes comuns de ensino regular" (BRASIL, 1996).

O Decreto № $3.298 / 99^{5}$, em seu artigo 24, inciso II, determina a inclusão no sistema educacional da educação especial como modalidade de educação escolar que permeia transversalmente todos os níveis e as modalidades de ensino. De acordo com o artigo 25:

\footnotetext{
Os serviços de educação especial serão ofertados nas instituições de ensino público ou privado do sistema de educação geral, de forma transitória ou permanente, mediante programas de apoio para o aluno que está integrado no sistema regular de ensino, ou em escolas especializadas exclusivamente quando a educação das escolas comuns não puder satisfazer as necessidades educativas ou sociais do aluno ou quando necessário ao bem-estar do (BRASIL, 1989, art. 25)
}

Em 2001, a Lei № 10.172 que trata do Plano Nacional de Educação (PNE) chama a atenção para a importância do atendimento precoce como forma preventiva e a necessidade que há em detectar as deficiências que podem dificultar a aprendizagem escolar. Na sequência, a resolução que institui as Diretrizes Nacionais para a Educação Especial na Educação Básica - 2001 assegura, em seu artigo 4, inciso II, a Educação Especial como modalidade da Educação Básica.

\subsection{Marcos legais e normativos: 2007 a 2020}

Voltando o olhar agora para o ano de 2007, é lançado, nesse ano, o Plano de Desenvolvimento da Educação (PDE) com 28 diretrizes que orientam as ações

\footnotetext{
${ }^{4}$ (Redação dada pela Lei № 12.796, de 2013).
} 
do Plano de Metas Compromisso 'Todos pela Educação'. Em seu plano de metas, estabelece como foco a aprendizagem o fortalecimento da inclusão educacional das pessoas com deficiência, como a implantação de salas de recursos multifuncionais, a acessibilidade arquitetônica dos prédios escolares, acesso e a permanência das pessoas com deficiência na educação superior.

$\mathrm{Na}$ diretriz IX, garante $\mathrm{O}$ acesso e permanência das pessoas com necessidades educacionais especiais nas classes comuns do ensino regular, fortalecendo a inclusão educacional nas escolas públicas ${ }^{6}$. Assim, conforme se pode perceber, é esse documento que efetiva a presença de alunos com deficiência nas classes regulares de ensino.

A Convenção sobre os Direitos das Pessoas com Deficiência (2009) ${ }^{7}$ afirma que os países são responsáveis por garantir um sistema de Educação Inclusiva em todas as etapas de ensino. No artigo 24 , que trata da educação, diz

Os Estados Partes assegurarão às pessoas com deficiência a possibilidade de adquirir as competências práticas e sociais necessárias de modo a facilitar às pessoas com deficiência sua plena e igual participação no sistema de ensino e na vida em comunidade (BRASIL, 2009, art. 19).

A Resolução № 4 CNE/CEB de $2009^{8}$ orienta o estabelecimento do atendimento educacional especializado (AEE) na Educação Básica e aponta que esse deve ser realizado no contraturno e, preferencialmente, nas chamadas salas de recursos multifuncionais das escolas regulares. De acordo com o artigo $5^{\circ}$ dessa resolução,

\footnotetext{
${ }^{5}$ Regulamenta a Lei no 7.853 , de 24 de outubro de 1989, dispõe sobre a Política Nacional para a Integração da Pessoa Portadora de Deficiência, consolida as normas de proteção, e dá outras providências.

6 Ver Decreto № $6.094 / 07$

7 Ver Decreto № 6.949/09 que promulga a Convenção Internacional sobre os Direitos das Pessoas com Deficiência e seu Protocolo Facultativo, assinados em Nova York, em 30 de março de 2007.

${ }^{8}$ Institui Diretrizes Operacionais para o Atendimento Educacional Especializado na Educação Básica, modalidade Educação Especial.
} 


\title{
$2021 / 02$
}

\section{ISSN 2178-6925}

\begin{abstract}
O AEE é realizado, prioritariamente, na sala de recursos multifuncionais da própria escola ou em outra escola de ensino regular, no turno inverso da escolarização, não sendo substitutivo às classes comuns, podendo ser realizado, também, em centro de Atendimento Educacional Especializado da rede pública ou de instituições comunitárias, confessionais ou filantrópicas sem fins lucrativos, conveniadas com a Secretaria de Educação ou órgão equivalente dos Estados, Distrito Federal ou dos Municípios. (BRASIL, 2009, art. 5)
\end{abstract}

O Decreto № $7.611 / 11^{9}$ estabelece novas diretrizes para o dever do Estado com a Educação das pessoas público-alvo da Educação Especial. Em seu artigo $3^{\circ}$, apresenta os objetivos do atendimento educacional especializado, dentre eles a garantia da transversalidade das ações da educação especial no ensino regular. Da mesma forma, assegura condições para a continuidade de estudos nos demais níveis, etapas e modalidades de ensino.

Com base nesses marcos constitucionais, o Plano Nacional de Educação (PNE) de 2014 tem como diretriz em seu artigo 1, inciso II, a universalização do atendimento escolar e, no inciso III, a superação das desigualdades educacionais, com ênfase na promoção da cidadania e na erradicação de todas as formas de discriminação. O PNE abre uma discussão muito forte para as políticas públicas e sociais.

A Lei Brasileira de Inclusão № 13.146/2015 aponta grandes desafios para a Educação Especial, que é essencial para que a inclusão aconteça. Em seu capítulo IV, que trata do direito à educação, ressalta, no artigo 27 , que

A educação constitui direito da pessoa com deficiência, assegurados sistema educacional inclusivo em todos os níveis e aprendizado ao longo de toda a vida, de forma a alcançar o máximo desenvolvimento possível de seus talentos e habilidades físicas, sensoriais, intelectuais e sociais, segundo suas características, interesses e necessidades de aprendizagem (BRASIL, 2015, art. 27).

\footnotetext{
${ }^{9}$ Revoga o decreto № 6.571 de 2008
} 


\section{Revista Multidisciplinar do Nordeste Mineiro, v.2}

\section{$2021 / 02$}

\section{ISSN 2178-6925}

As especialidades da Educação Inclusiva merecem um olhar diferenciado para garantir a permanência do sujeito na sala de aula. De acordo com o artigo 28, inciso IX, da Lei Brasileira de inclusão,

"A adoção de medidas de apoio que favoreçam o desenvolvimento dos aspectos linguísticos, culturais, vocacionais e profissionais, levando-se em conta o talento, a criatividade, as habilidades e os interesses do estudante com deficiência" (BRASIL, 2015, art. 28).

A Base Nacional Comum Curricular - BNCC (2017) define a escola como espaço de aprendizagem e de democracia inclusiva que deve se fortalecer na prática coercitiva de não discriminação, sem preconceito e respeito às diferenças e diversidades. No entanto, a BNCC negligencia a Educação Inclusiva, pois não traz nenhuma competência voltada exclusivamente para a Educação Especial.

Conforme se pode perceber, a partir de uma análise sócio-histórica desses documentos, eles contribuíram muito para mudar a visão acerca dos indivíduos com deficiência. Apesar disso, incluir de fato os alunos especiais ainda é uma dificuldade para grande parte dos professores, que, na maioria das vezes, não dispõem de uma formação que lhes prepare para a educação especial.

\section{MÉTODO}

A pesquisa aqui empreendida caracteriza-se por ser de cunho bibliográfico, sendo embasada teoricamente em leituras. Segundo Marconi e Lakatos, (1991) a pesquisa bibliográfica diz respeito ao levantamento de toda a bibliografia já publicada e que tenha relação com o tema em estudo. Assim, tem como finalidade colocar o pesquisador em contato direto com tudo aquilo que já foi escrito.

Para a realização da pesquisa, foram selecionados três periódicos que hospedam artigos e trabalhos científicos das mais diferentes áreas, são eles: Scientific Electronic Library Online (SciELO); Google Acadêmico; e Teses e Dissertações da Coordenação de Aperfeiçoamento de Pessoal de Nível Superior (CAPES). Em todos os sites, foram digitadas no campo de pesquisa as palavras- 
chave "deficiência intelectual" ou "deficiência mental" e "avaliação". Em algumas ocasiões, também foram utilizados filtros de pesquisa, buscando selecionar apenas os trabalhos referentes à área da Educação, de maneira a contemplar o objetivo deste estudo, sem tornar a busca exaustiva.

A escolha de analisar os textos alocados nos referidos sites deu-se pelo entendimento de que eles estão mais acessíveis aos professores do que livros publicados por editoras, por exemplo. Assim, neste trabalho, foram contempladas as reflexões apresentadas pelos trabalhos, oportunizando, logo, o conhecimento deles, bastando, se houver a necessidade de ler na íntegra, realizar uma breve busca nesses sites.

Para a realização da presente pesquisa, foram selecionados artigos que tratavam da avaliação, seja através de pesquisa de campo, etnográfica ou de outra natureza. No entanto, cabe salientar que o que interessava nesses trabalhos era a teorização proposta pelo autor para avaliação e não possíveis demonstrações de concepções que tinham os professores a respeito da avaliação, por exemplo. Não que, neste trabalho, não sejam apontados alguns dos resultados e reflexões obtidas com as referidas pesquisas, mas o objetivo principal era focar somente na parte teórica apresentada nos textos. Assim, esta pesquisa contempla apenas essa parte teórica, deixando de lado as pesquisas feitas pelos autores daqueles trabalhos.

Os critérios de exclusão aplicados a essa pesquisa voltaram-se para os trabalhos dedicados à avaliação de apenas uma competência, como leitura e escrita, coordenação motora etc, bem como a textos relacionados a outras áreas, que não à Educação. Da mesma forma, foram excluídos da análise textos que propunham também uma pesquisa bibliográfica sobre o tema, pois o intuito não era partir de uma pesquisa bibliográfica que já constava nestes trabalhos, mas sim, através das concepções de seus autores sobre o conceito de avaliação dos alunos deficiência intelectual, construir a presente. Outro critério utilizado para excluir alguns trabalhos encontrados, foi em relação a artigos cujo título referia-se à avaliação, mas não apresentavam uma conceituação consistente sobre ela. 
TABELA 1 - QUANTIDADE DE TRABALHOS CIENTÍFICOS SOBRE DEFICIÊNCIA INTELECTUAL ENCONTRADOS EM PERÍODICOS

\begin{tabular}{|c|c|c|c|c|}
\hline Ano & Artigo científico & Dissertação & Tese & Capítulo de livro \\
\hline 2007 & - & 01 & - & - \\
\hline 2008 & - & - & - & 02 \\
\hline 2009 & - & - & - & - \\
\hline 2010 & 01 & - & - & - \\
\hline 2011 & - & 02 & - & - \\
\hline 2012 & 01 & - & - & - \\
\hline 2013 & 01 & - & - & 02 \\
\hline 2014 & 01 & 02 & - & - \\
\hline 2015 & - & - & 01 & - \\
\hline 2016 & 02 & 01 & - & - \\
\hline 2017 & - & 02 & - & - \\
\hline 2018 & 01 & - & - & 01 \\
\hline 2019 & - & - & - & - \\
\hline 2020 & - & - & - & - \\
\hline Total & 07 & 08 & 01 & 05 \\
\hline
\end{tabular}

Fonte: Dados da pesquisa (2020).

Assim, como se pode perceber, no total, foram analisados 21 trabalhos voltados à avaliação da aprendizagem de alunos com deficiência intelectual, dentre eles artigos, teses, dissertações e capítulos de livros. Na tabela 1 é possível conferir detalhadamente o número de trabalhos analisados nesta pesquisa e podese verificar a quantidade, bem como a natureza dos trabalhos encontrados em cada ano pesquisado.

\section{RESUltados E DISCUSSÕES: A AVALIAÇÃO DOS ALUNOS COM DEFICIÊNCIA INTELECTUAL (2007 A 2020)}

$\mathrm{Na}$ perspectiva de Souza (2007), a avaliação permite que se realize o diagnóstico através de um processo de avaliação que engloba as potencialidades dos alunos. A autora aponta a atenção dada por Vygotsky às pessoas com deficiência, pois suas críticas recaiam sobre o diagnóstico da criança com deficiência mental ser impreciso - o que se verifica até hoje - e pautar-se mais nas 
limitações da criança (aquilo que ela não é, aquilo que ela não sabe fazer) do que nas suas possibilidades.

No ano de 2007, o trabalho de Souza foi o único encontrado no que diz respeito à avaliação de alunos com deficiência intelectual. Isso demonstra um déficit de entendimento sobre o processo de avaliação. Já nos anos seguintes, percebe-se um maior número de publicações envolvendo esse processo.

O Referencial do Estado de São Paulo (2008), em relação à avaliação, nos diz que

\begin{abstract}
Cabe a escola a preocupação em adequar os diferentes instrumentos de avaliação para que possa permitir também a avaliação de alunos com deficiência intelectual, de modo a conhecer o que o aluno aprendeu, a analisar as variáveis implícitas no processo de ensino e aprendizagem. As estratégias de avaliação também deverão permitir avaliar as necessidades específicas dos alunos com deficiência intelectual e os apoios necessários para que possa se garantir a sua aprendizagem, com base nos objetivos educacionais, mesmo que com adequações (SÃO PAULO, 2008, p. 32).
\end{abstract}

Assim, entende-se a importância das observações realizadas pelo professor no cotidiano escolar, pois, para ele, "o professor deve aprimorar seu olhar para o potencial do aluno, observar suas condições de aprendizagem, suas evoluções, seu desempenho escolar, sem que seja necessário criar situações artificiais de avaliação" (SÃO PAULO, p. 33).

Percebe-se que o documento mostra para a importância da observação cotidiana no processo de avaliação do aluno com deficiência intelectual. Além disso, o referencial aponta outra estratégia de avaliação, que consiste na análise da produção escolar desse aluno, como seus cadernos, folhas de exercícios, desenhos, figuras, relatos orais e outros trabalhos realizados em sala de aula.

Macedo (2010) mostra a padronização do processo de avaliação praticado nas escolas em que se busca avaliar todos os alunos a partir do mesmo método: provas que buscam identificar quem aprendeu e quem não aprendeu. Tais avaliações são utilizadas para classificar os alunos, através de um padrão préestabelecido, assim, "se decide reprovar ou excluir alunos com um mau 
desempenho ou com desempenho abaixo do esperado, assim como avançar outros, considerados aptos" (MACEDO, 2010, p. 5).

A avaliação da aprendizagem dos alunos com deficiência, de acordo com Livramento (2011), deve ser pautada não em quantificar, mas sim perceber como se deu o processo educativo, analisando se houve ou não êxito na aprendizagem, elaborando, se necessário, novas estratégias que garantam a aprendizagem por parte do aluno. Assim, a avaliação deve sempre partir de pressupostos que considerem as potencialidades do aluno e não suas deficiências. A autora diz, baseada em Carneiro (2007, p.157), que a avaliação necessita "necessariamente, de ser dinâmica, contínua, mapeando o processo de aprendizagem dos alunos em seus avanços, retrocessos, dificuldades e progressos". Além disso, na perspectiva de Livramento (2014) deve-se tomar a avaliação em seu caráter Processual, Diagnóstica, Formativa, Participativa e Cumulativa.

Valentim (2011) destaca que, quando o aluno com deficiência intelectual é submetido a testes e provas não adaptados às suas especificidades e apenas com fins quantitativos, ele é colocado em uma classificação indevida e desnecessária e a escola acaba por concebê-lo como pior no desempenho escolar, ao invés de utilizar a avaliação para planejar ações que poderiam ser realizadas para melhorar o processo de ensino e aprendizagem desse sujeito.

A mesma autora chama a atenção para a importância do ciclo avaliativo, definido por ela como aquele que "constitui-se em uma totalidade de ações e instrumentos que, se utilizados juntos, podem auxiliar a prática pedagógica, de forma a orientá-la e subsidiá-la na tomada de decisões acerca da aprendizagem dos alunos" (VALENTIM, 2011, p. 33). Assim, os momentos de avaliação devem ocorrer durante a aula, como a realização de atividades em grupo, leitura de textos, atividades escritas, dentre outras. Ao promover um ciclo de avaliação, deve-se considerar o aluno durante todo o seu percurso de aprendizagem e não somente seu desenvolvimento em determinado momento do processo. Assim, surge a utilização de outros instrumentos avaliativos que não somente provas e testes, como os relatórios, os portfólios e as observações. 
Durli (2012, p. 2) possui uma visão similar à de Livramento, uma vez que explica que "o professor deve aprimorar o seu olhar para o potencial do aluno, observar suas condições de aprendizagem, suas evoluções, seu desempenho escolar".

Já Ferreira e Costa (2013) apontam algumas direções na avaliação inclusiva que devem ser seguidas pelos professores em sala de aula. São elas:

a) Melhorar a dinâmica da sala de aula consultando o portfólio dos alunos para elaborar as atividades;

b) Evitar testes padronizados;

c) Envolver a família no processo de avaliação;

d) Não utilizar a avaliação como um processo de classificação;

e) Incorporar o sentido ético e inclusivo na avaliação.

Oliveira, Dourado e Silva (2013) mencionam que a observação é o mais recomendado, no contexto educacional, para a coleta de informações, mas outros instrumentos também podem ser utilizados. Assim, deve a escola adotar uma postura dinâmica de acompanhamento, de registro, visando a identificar as possibilidades dos alunos, bem como reconhecer as suas condições de aprendizagem e identificar as áreas que estão em desenvolvimento.

Milanez e Oliveira (2013), em documentos elaborados pela Secretaria Municipal de Educação de São Paulo (SÃO PAULO, 2008; 2012), insistem na premente necessidade de uma avaliação abrangente que considere a instituição escolar (conhecimentos prévios sobre o aluno, recursos e materiais específicos, definição de cronograma de ações), a ação pedagógica (a sala de aula, os recursos e materiais de aprendizagem, as estratégias metodológicas) e o aluno (suas características funcionais e suas competências curriculares). Em relação ao que avaliar quando se trata de um aluno com deficiência intelectual, as autoras dizem que se deve buscar avaliar: 
“1) função cognitiva: percepção, atenção, memória, linguagem, raciocínio lógico;

2) função pessoal-social: estado emocional, reação a frustração, isolamento, medos; interação grupal, cooperação, afetividade." (MILANEZ; OLIVIERA, 2013, p. 22).

Mendonça (2014) comenta sobre a importância da avaliação formativa, destacando o processo de dialogicidade, intrínseca a ela, permitindo que o professor acompanhe a aprendizagem dos alunos e possa realizar intervenções e reajustes no processo de ensino e aprendizagem. Ressalta, ainda, que a avaliação do aluno com deficiência intelectual deve ser contínua e processual, sempre valorizando as aprendizagens adquiridas no seio familiar, social e escolar, fazendo com que elas sirvam como ponto de partida para o planejamento do trabalho docente.

Pletsch e Oliveira (2014) fazem uma crítica a respeito das práticas de avaliações tradicionais que ainda são realizadas com os alunos com deficiência. De acordo com elas,

A avaliação deve ir além do ato de verificar e classificar, pois um ensino baseado apenas no que já foi produzido, em detrimento às ações que poderiam ser realizadas pela escola, não favorecerá o processo de ensino e aprendizagem dos sujeitos com ou sem deficiência. "(PLETSCH; OLIVEIRA, 2014, p. 130-131).

Nesse sentindo, Terra (2014) fala sobre a necessidade de a avaliação ter por objetivo não somente a verificação de conhecimentos já adquiridos, mas também a identificação das capacidades e potencialidades do aluno com deficiência intelectual, "de forma a subsidiar o planejamento e a execução de interações e de ações interventivas, com vistas à superação de dificuldades e à promoção de novas aprendizagens" (TERRA, 2014, p. 60).

Aguiar (2015, p. 201) chama a atenção para a prática de aprovação automática, "justamente para justificar o não fazer pedagógico, principalmente com os alunos público-alvo da Educação Especial ou aqueles que apresentam dificuldades de aprender". O que prova consequências graves no contexto escolar, sobretudo para os alunos com deficiência intelectual. Para a autora, a avaliação é 
um processo de reflexão sobre a mediação e a apropriação do conhecimento, que deve se dar através de uma relação dialética, entre alunos e professores; e os instrumentos dessa avaliação são plurais.

No estudo de Anache e Resende (2016), foi possível observar que a avaliação da aprendizagem se caracteriza como um processo "contínuo e interventivo", que possibilita identificar o que o aluno é capaz de fazer em sala de aula e fora dela, com ou sem os apoios necessários.

Oliveira (2016) traz algumas concepções de avaliação que ajudam a pensar o processo de ensino-aprendizagem dos alunos com deficiência intelectual. Ela apresenta a avaliação assistida, entendendo-a como uma avaliação dinâmica, mediada e fundamental para a interação entre professor e aluno e as trocas pertinentes ao desdobramento educativo. Nesse processo de avaliação, é necessário que o professor tenha clareza dos objetivos e dos critérios avaliativos, considerando o que o aluno é capaz de fazer sozinho e o que é capaz de fazer com a ajuda do outro, percebendo como o aluno, através do auxílio que recebe nesse momento, é capaz de transformar a mesma em algo significativo. Oliveira (2016) ainda destaca a importância das avaliações periódicas, pois permitem, com frequência, fornecer elementos para eventuais revisões das intervenções e mediações pedagógicas. Assim, quando aplicada adequadamente, pode proporcionar o desenvolvimento de ações e práticas que favorecem a aprendizagem dos alunos com deficiência intelectual.

Vitorino e Grego (2016) chamam a atenção para a necessidade de se romper com práticas tradicionais de avaliação. Para elas, a avaliação formativa independe do tipo de avaliação que vai ser aplicada (testes, provas ou trabalhos). O que importa é registrar o desenvolvimento do aluno, através de um olhar individualizado para cada um, com seus avanços e dificuldades. Além disso, tais constatações devem servir para redirecionar o trabalho docente, sempre que necessário. As autoras sugerem o uso do portfólio por possibilitar o registro de cada atividade realizada pelos alunos no cotidiano da sala de aula. 
Luz (2017) afirma que um dos princípios da avaliação formativa é abandonar o uso autoritário da avaliação "como verificação e controle das aprendizagens discentes em nome de uma perspectiva sociointeracionista" (LUZ, 2017, p. 43). A pesquisa realizada pela autora revelou que diminuir a extensão das provas não é suficiente para acompanhar as aprendizagens dos alunos, mas apenas possibilita cumprir exigências e facilitar o desempenho deles.

Albuquerque (2017) acredita que os momentos de avaliação devem ser contínuos, de modo a captar suas possibilidades de aprendizagem, assim como os instrumentos devem ser adaptados, a fim de avaliar e acompanhar o que ele é capaz de fazer sozinho e/ou com ajuda, oferecendo informação para atuar nas suas necessidades. O autor aponta a necessidade de se respeitar as particularidades de cada aluno e diz que as especificidades dos alunos independentes de sua condição física, motora ou intelectual devem ser respeitadas no momento de elaboração e de aplicação da avaliação. Albuquerque (2017) ainda salienta o fato de nenhum aluno ser igual ao outro, ainda que possua a mesma deficiência e, assim, diz que uma mesma estratégia avaliativa pode sim ser usada com diferentes alunos ou então ajustada, mas sempre respeitando as individualidades. Portanto, deve-se eliminar os rótulos e a comparação entre os alunos tomando como critério de avaliação o próprio aluno e suas reais necessidades.

Marin e Braun (2018) citam, primeiramente, a avaliação mediada envolvendo o acompanhamento do docente durante a realização da atividade, o que permite garantir a atenção e o envolvimento do aluno. Assim, tal atividade desdobrava-se em diversas outras, como a leitura compartilhada e a leitura de enunciado. Estar junto com o estudante, dizem as autoras, "significa estar com ele para compreender seus raciocínios e percursos mentais, para agir de modo ajustado, em razão de suas demandas." (MARIN; BRAUM, 2018, p. 1018). Nessa avaliação mediada, dizem elas, devem ser realizados registros, seja através de diários ou de relatórios. Da mesma forma, as autoras demonstram a importância de ajustar os instrumentos de avaliação, como, por exemplo, o uso de enunciados mais diretos, o uso de 
imagens etc. Outro ponto importante, segundo elas, é a flexibilização do tempo, permitindo que a atividade seja realizada em mais tempo. Em relação a atribuição de notas, as autoras comentam que ela pode ser realizada de maneira diferente, entendo que "precisam considerar o estudante em relação a ele mesmo, analisando seu próprio desenvolvimento. A turma não é um parâmetro de comparação que favoreça essa análise sobre o desempenho do estudante com deficiência intelectual" (MARIN; BRAUM, 2018, p. 1019).

Santos e Albuquerque (2018) destacam a observação como ferramenta sugerida para a coleta de informações a respeito do aluno. Outro importante método de avaliação desses alunos abordados pelos autores é a investigação da produção escolar dos mesmos, como cadernos, folhas de exercícios etc. Da mesma forma, sugerem diários de bordo, relatórios, entrevistas e outros que possibilitem conhecer a capacidade de aprendizagem desses alunos e diferenciar desenvolvimento real e desenvolvimento potencial.

A partir da análise dessas 21 pesquisas publicadas entre 2007 - 2020, os estudos mostram uma grande preocupação por parte dos educadores ao tratar alunos com deficiência intelectual nas salas regulares. Foram apresentados diversos tipos de avaliação, como a diagnóstica, processual, contínua, formativa, dinâmica, assistida, mediada e periódicas. Além disso, muitos desses pesquisadores criticaram as formas tradicionais de avaliação e muitos destacam a observação como uma das várias formas para chegar à avaliação de forma justa, ou seja, respeitando os limites dos alunos com deficiência intelectual.

\section{CONSIDERAÇÕES FINAIS}

A pesquisa revelou, a priori, o quanto ainda faltam trabalhos na área da avaliação da aprendizagem de pessoas com deficiência intelectual. Conforme observou-se, o maior número de publicações na área reúne-se em 2015-2017 e, nos últimos anos, há uma redução significativa, tanto que não foram encontrados trabalhos nos anos de 2019 e 2020. Dessa forma, percebe-se a importância de 


\section{Revista Multidisciplinar do Nordeste Mineiro, v.2}

\section{$2021 / 02$}

\section{ISSN 2178-6925}

fomentar novas pesquisas nessa área que possam expandir esse campo de estudo, uma vez que a Educação Inclusiva vem ganhando mais espaço no cenário brasileiro e, portanto, necessita de estudos que contribuam com a prática docente.

Em relação aos trabalhos analisados, percebe-se a importância em tentar promover práticas de avaliação da aprendizagem que sejam condizentes com as especificidades dos alunos com deficiência intelectual, sempre os compreendendo não em termos de limitações, mas sim de condições de desenvolvimento. Deve-se considerar esse aluno não a partir do que ele não faz, mas sim do que ele pode fazer, haja vista que esses alunos têm um ritmo próprio de aprendizagem que merece um olhar diferenciado por parte da escola. Assim, um dos teóricos mais citados para auxiliar a compreender a noção de avaliação foi Vygotsky. As contribuições desse filósofo recaem sobre os conceitos de Zona de Desenvolvimento Real e Potencial, a partir das quais, explicam os autores, o professor deve agir.

Além disso, foi possível observar que diversos autores mencionaram a respeito da complexidade do processo de avaliar, tanto os alunos com deficiência, quanto os ditos "normais". Assim, na maioria dos trabalhos analisados, a sugestão foi aplicar variadas formas de avaliação da aprendizagem de alunos com deficiência intelectual, favorecendo, assim, a inclusão e respeitando a maneira de lidar com o saber de cada um. Além disso, muitos apontaram o fato de que não há um único instrumento existente quando se fala em avaliação, mas sim diferentes instrumentos que se colocam a serviço do professor, necessitando que esse, através de uma análise minuciosa e crítica de seu contexto, decida qual é o mais adequado.

\section{REFERÊNCIAS}


AGUIAR, A. M. B. Calcanhar de aquiles: a avaliação do aluno com deficiência intelectual no contexto escolar. 2015. Tese (Doutorado em Educação) - Centro de Educação, Universidade Federal do Espírito Santo, Espírito Santo. $261 \mathrm{f}$.

ALBUQUERQUE, Richardson Batalha. "Sei ou não sei, eis a questão" o professor e seu saber fazer na perspectiva da avaliação da aprendizagem para alunos com deficiência intelectual. 2017. Dissertação (Mestrado em Educação) - Programa de Pós-graduação em Educação, Universidade Federal de Sergipe, São Cristóvão.

ALLES, Elisiane Perufo et al. (Re)Significações no Processo de Avaliação do Sujeito Jovem e Adulto com Deficiência Intelectual. Rev. bras. educ. espec., Bauru, v. 25, n. 3, p. 373-388, Sept. 2019. Disponível em: https://www.scielo.br/scielo.php?pid=S141365382019000300373\&script=sci arttext \#B12. Acesso em: 12 jul. 2020.

ANACHE, Alexandra Ayach; RESENDE, Dannielly Araújo Rosado. Caracterização da avaliação da aprendizagem nas salas de recursos multifuncionais para alunos com deficiência intelectual. In: Revista Brasileira de Educação v. 21 n. 66 jul.-set. 2016.

BRASIL. Constituição da República Federativa do Brasil. Brasília, DF. 1988. Disponível em: http://www.planalto.gov.br/ccivil03/constituicao/constituicao.htm Acesso em: 05 jul.2020 . Ministério da Educação. Secretaria de Educação Especial. Lei №. 7.853, de 24 de outubro de 1989. Disponível em: http://www.planalto.gov.br/ccivil 03/leis/L7853.htm. Acesso em: 05 jul.2020 


\section{1/02}

\section{ISSN 2178-6925}

. Estatuto da Criança e do Adolescente no Brasil. Lei no 8.069, de 13 de julho de 1990. Disponível em: http://www.planalto.gov.br/ccivil03/leis/l8069.htm Acesso em: 05 jul. 2020.

Declaração de Salamanca e linha de ação sobre necessidades educativas especiais. Brasília: UNESCO, 1994.

. Lei n. 9394, de 20 de Dezembro de 1996. Estabelece as Diretrizes e Bases da Educação Nacional. Brasília, DF, 1996. Diário Oficial da República Federativa do Brasil. Brasília, DF, 23 dez. 1996.

. Decreto no 3.298, de 20 de dezembro de 1999. Disponível em: http://www.planalto.gov.br/ccivil03/decreto/D3298.htm Acesso em: 05 jul.2020

- Ministério da Educação. Referencial curricular nacional para a educação infantil: estratégias e orientações para a educação de crianças com necessidades educacionais especiais. Brasília: MEC, 2000. Disponível em: http://portal.mec.gov.br/seb/arquivos/doc/eduinf esp ref.doc. Acesso em: 11 jul. 2020.

. Diretrizes nacionais para a educação especial na educação básica. Brasília, 2001 MEC, Disponível em: http://portal.mec.gov.br/arquivos/pdf/resolucao2.pdf. Acesso em: 20 jul. 2020

. Plano Nacional de Educação. Lei no 10.172, de 09 de janeiro de 2001. Disponível em: http://www.planalto.gov.br/ccivil_03/leis/leis_2001/110172.htm Acesso em: 06 jul.2020. 
Revista Multidisciplinar do Nordeste Mineiro, v.2

\section{$2021 / 02$}

ISSN 2178-6925

. Decreto no 6.094, de 24 de abril de 2007. Disponível em: http://www.planalto.gov.br/ccivil 03/ Ato2007-2010/2007/Decreto/D6094.htm Acesso em: 06 jul.2020.

. Formação Continuada a Distância de Professores para o Atendimento Educacional Especializado Deficiência Mental. Brasília, MEC/SEESP, 2007.

. Política Nacional de Educação Especial na Perspectiva da Educação Inclusiva. Brasília: MEC/2008.

.DECRETO № 6.949, DE 25 DE AGOSTO DE 2009. Disponível em: http://www.planalto.gov.br/ccivil 03/ ato2007-2010/2009/decreto/d6949.htm Acesso em: 06 ago.20.

. RESOLUÇÃo № 4, DE 2 DE OUTUBRO DE 2009. Disponível em: http://portal.mec.gov.br/dmdocuments/rceb004 09. Acesso em: 06/07/20

DECRETO № 7.611, DE 17 DE NOVEMBRO DE 2011. Disponível: http://www.planalto.gov.br/ccivil 03/ ato2011-2014/2011/decreto/d7611.htm. Acesso em 05 ago.2020

. Plano Nacional de Educação - Lei $n^{\circ}$ 13.005/2014. Disponível em: http://pne.mec.gov.br/18-planos-subnacionais-de-educacao Acesso em: 07 ago.20.

. Lei Federal 13.146/15. Lei Brasileira de Inclusão. 2015. Disponível em: http://www.planalto.gov.br/ccivil 03/ ato2015-2018/2015/lei//13146.htm Acesso em: 07 set. 2020. 


\section{Revista Multidisciplinar do Nordeste Mineiro, v.2}

\section{$2021 / 02$}

\section{ISSN 2178-6925}

- Base Nacional Comum Curricular (BNCC). Educação é a Base.

Brasília, MEC/CONSED/UNDIME, 2017. Disponível em:

http://basenacionalcomum.mec.gov.br/ Acesso em: 07 set. 2020.

DUARTE, Regina Célia Beltrão. Deficiência intelectual na criança. In: Residência Pediátrica. 17-25. 2018.

DURLI, Tânia Mara Bergamo. Avaliação Escolar e aprendizagem da criança com Deficiência Intelectual. Revista de Educação do IDEAU, v. 7, n. 16 - Julho Dezembro 2012.

FERREIRA, Maria Luíza Dian; COSTA, Gisele Maria Tonin. Avaliação e deficiência intelectual. Revista de Educação do IDEAU, v. 8, n. 17 - Janeiro - Junho, 2013.

FREIRE, Paulo. Pedagogia do Oprimido. 17a ed. Rio de Janeiro: Paz e Terra, 2006.

LIVRAMENTO, Maria Zélia Corado. Formação continuada dos professores como subsídio para ensinar e avaliar a aprendizagem dos alunos com deficiência intelectual. 2014. Monografia (Especialização em Gestão Educacional) Curso de aperfeiçoamento de Profissionais da Educação, Universidade de Brasília. $59 f$.

LIVRAMENTO, Solange Pereira. Concepções e Práticas em Avaliação do Processo ensino e aprendizagem de educandos com Deficiência Intelectual nas Classes Comuns dos Anos/séries Iniciais, no Município de Macapá-AP. 2011. Dissertação (Mestrado em Ciências da Educação - Avaliação Educacional) Departamento de Pedagogia e Educação, Universidade de Évora, Évora. 372 f. 
LUZ, Lelyane Silva. Procedimentos avaliativos no processo de escolarização de uma estudante com deficiência intelectual. 2017. Dissertação (Mestrado em Educação) - Programa de Pós Graduação em Educação, Universidade Federal de Uberlândia, Uberlândia. $149 f$.

MACEDO, Angela Santos; BARBY, Ana Aparecida de Oliveira Machado. Reflexões e Alternativas Pedagógicas para a Avaliação do Aluno Deficiente Intelectual Incluído no Sistema Comum de Ensino. In: Secretaria Estadual de educação do Paraná - O professor PDE e os desafios da escola pública paranaense. Vol. 1. 2010.

MARCONI, M. A.; Lakatos, E. M. Fundamentos de metodologia científica. 3.ed. São Paulo: Atlas, 1991.

MARIN, Márcia; BRAUN, Patrícia. Avaliação da aprendizagem em contextos de inclusão escolar. Revista Educação Especial, v. 31, n. 63, out/dez. 2018. p. 10091024.

MENDONÇA, Andréia Vieira de. Desenvolver potenciais e valorar capacidades: avaliação da aprendizagem de alunos com deficiência intelectual em escolas municipais de Fortaleza-CE. 2014. Dissertação (Mestrado em Educação) Programa de Pós-Graduação em Educação, Universidade Federal do Ceará. 144f.

MILANEZ, Simone Ghedini; OLIVEIRA, Anna Augusta Sampaio; Atendimento Educacional Especializado para alunos com Deficiência Intelectual: a Politica, as Concepcões e a Avaliação. In: MILANEZ, Simone Ghedini Costa; OLIVEIRA, Anna Augusta Sampaio de Oliveira; MISQUIATTI, Andrea regina Nunes. Atendimento educacional especializado para alunos com deficiência intelectual e transtornos globais do desenvolvimento. São Paulo: Cultura Acadêmica, 2013. 
NOGUEIRA, C. M. I; CARNEIRO, M. I. N; SOARES, B. I. N. Libras. Maringá: UniCesumar, 2017.

OLIVEIRA, Anna Augusta Sampaio; DOURADO, Fernanda Oscar; SILVA, Luis Henrique. Avaliação pedagógica: foco na deficiência intelectual em uma perspectiva inclusiva. São Paulo: Cultura Acadêmica, 2013.

OLIVEIRA, Mariana Corrêa Pitanga de. A escolarização de alunos com deficiência intelectual à luz da perspectiva histórico-cultural: avaliação mediada e apropriação conceitual. 2016. Dissertação (Mestrado) - Universidade Federal Rural do Rio de Janeiro. Programa de Pós-Graduação em Educação, Nova Iguaçu.

PLETSCH, M. D., \& GLAT, R. A escolarização de alunos com deficiência intelectual: uma análise da aplicação do Plano de Desenvolvimento Educacional Individualizado. 2012. Linhas Críticas, 18(35), 193-208. Disponível em:< $\quad$ https://periodicos.unb.br/index.php/linhascriticas/article/view/3847/3518>. Acesso em: 12 jul. 2020.

PletSCH, Márcia Denise; OlIVEIRA, Anna Augusta Sampaio. O Atendimento Educacional Especializado (AEE): análise da sua relação com o processo de inclusão escolar na área da Deficiência Intelectual. In: MILANEZ, Simone Ghedini Costa; et. al. Atendimento educacional especializado para alunos com deficiência intelectual e transtornos globais do desenvolvimento. São Paulo: Cultura Acadêmica, 2013.

PletSCH, Márcia Denise; OLIVEIRA, Mariana Corrêa Pitanga. Políticas de educação inclusiva: considerações sobre a avaliação da aprendizagem de alunos com deficiência intelectual. In: Revista Educação, Artes \& inclusão, vol. 10, n.2, 2014. 125-137. 
SANTOS, Danielle Neres; ALBUQUERQUE, Richardson Batalha. A avaliação para os alunos com deficiência Intelectual (DI): conceitos, concepções e práticas In: Souza, Rita de Cácia Santos; ALVES, Maria Dolores Fortes (orgs.). Aprendizagem e Deficiência Intelectual em foco - Discussões e pesquisas. Aracaju: Criação, 2018.

SÃO PAULO. Secretaria Municipal de Educação. Referencial sobre Avaliação da Aprendizagem na área da Deficiência Intelectual. Secretaria Municipal de Educação - São Paulo: SME / DOT, 2008.

SOUSA, Gabriela Maria Brabo. Avaliação inicial do aluno com deficiência mental na perspectiva inclusiva. 2007. Dissertação (mestrado em Educação) Programa de Pós-Graduação em Educação, Universidade Federal do Rio Grande do Sul, Porto Alegre.

TERRA, Maria Lúcia. A avaliação da aprendizagem escolar de estudantes com deficiência intelectual. 2014. Dissertação (Mestrado em Educação) - Programa de Pós-Graduação em Educação, Universidade Estadual Paulista Júlio de Mesquita Filho, Presidente Prudente. 230f.

VALENTIM, Fernanda Oscar Dourado. Inclusão de alunos com deficiência intelectual: considerações sobre avaliação da aprendizagem escolar. 2011. Dissertação (Mestrado em Educação) - Faculdade de Filosofia e Ciências, Universidade Estadual Paulista, São Paulo. $143 \mathrm{f}$

VITORINO, Stephânia Cottorello; GREGO, Sonia Maria Duarte. Avaliação formativa na educação inclusiva. In: Revista Ibero-Americana de Estudos em Educação, [S.I.], p. 478-488, may 2016. ISSN 1982-5587. Disponível em: 
Revista Multidisciplinar do Nordeste Mineiro, v.2

$2021 / 02$

ISSN 2178-6925

<https://periodicos.fclar.unesp.br/iberoamericana/article/view/8568>. Acesso em: 29 julho de 2020. doi:https://doi.org/10.21723/RIAEE.v11.esp.1.p478. 